\title{
BVDV alters uterine prostaglandin production during pregnancy recognition in cows
}

\author{
Zhangrui Cheng ${ }^{1}$, Ayimuguli Abudureyimu ${ }^{2}$, Chike F Oguejiofor ${ }^{1}$, Rebekah Ellis ${ }^{1}$, \\ Amy Teresa Barry ${ }^{1}$, Xing Chen ${ }^{1,3}$, Olivia L Anstaett ${ }^{4}$, Joe Brownlie ${ }^{4}$ and D Claire Wathes ${ }^{1}$ \\ ${ }^{1}$ Department of Production and Population Health, Royal Veterinary College, North Mymms, Hertfordshire, UK, \\ ${ }^{2}$ Life Science and Engineering College, Northwest University for Nationalities, Lanzhou, China, ${ }^{3}$ Key Laboratory of \\ Agricultural Animal Genetics, Breeding and Reproduction, Education Ministry of China, College of Animal Science \\ and Technology, Huazhong Agricultural University, Wuhan, China and ${ }^{4}$ Department of Pathology and Pathogen \\ Biology, Royal Veterinary College, North Mymms, Hertfordshire, UK
}

Correspondence should be addressed to Z Cheng; Email: zcheng@rvc.ac.uk

\begin{abstract}
Embryonic mortality in cows is at least in part caused by failure of pregnancy recognition (PR). Evidence has shown that bovine viral diarrhoea virus (BVDV) infection can disrupt pregnancy. Prostaglandins (PG) play important roles in many reproductive processes, such as implantation. The aim of this study was to investigate the effect of BVDV infection on uterine PG production and PR using an in vitro PR model. Bovine uterine endometrial cells isolated from ten BVDV-free cows were cultured and treated with 0 or $100 \mathrm{ng} / \mathrm{mL}$ interferon- $\tau$ (IFNT) in the absence or presence of non-cytopathic BVDV (ncpBVDV). PGF ${ }_{2 \alpha}$ and $\mathrm{PGE}_{2}$ concentrations in the spent medium were measured using radioimmunoassays, and in the treated cells expression of the genes associated with PG production and signalling was quantified using qPCR. The results showed that the IFNT challenge significantly stimulated PTGS1 and PTGER3 mRNA expression and PGE $_{2}$ production; however, these stimulatory effects were neutralised in the presence of ncpBVDV infection. ncpBVDV infection significantly increased PTGS1 and mPGES1 mRNA expression and decreased $A K R 1 B 1$ expression, leading to increased $P_{G E}$ and decreased $P_{2} F_{2 \alpha}$ concentrations and an increased $\mathrm{PGE}_{2}: \mathrm{PGF}_{2 \alpha}$ ratio. The other tested genes, including PGR, ESR1, OXTR, PTGS2, PTGER2 and PTGFR, were not significantly altered by IFNT, ncpBVDV or their combination. Our study suggests that BVDV infection may impair PR by (1) inhibiting the effect of IFNT on uterine PG production and (2) inducing an endocrine switch of PG production from $\mathrm{PGF}_{2 \alpha}$ to $\mathrm{PGE}_{2}$ to decrease uterine immunity, thereby predisposing the animals to uterine disease.

Reproduction (2016) 151 605-614
\end{abstract}

\section{Introduction}

Poor reproductive performance, of which early embryonic mortality is a major component, causes major economic loss to the dairy industry (De Vries 2006). Embryonic mortality rates in cattle can be as high as $40 \%$, with $70-80 \%$ of losses occurring before day 16 of gestation (Diskin et al. 2011). Following successful ovulation and subsequent fertilisation, production of interferon- $\tau$ (IFNT) by the trophectoderm begins at around day 8 of gestation and increases dramatically during conceptus elongation (Kimura et al. 2004). A sufficient threshold level of IFNT must be reached by day 16 to ensure pregnancy recognition (PR) and prevention of luteolysis (Forde et al. 2011, Lonergan \& Forde 2014). IFNT acts in a paracrine manner on the uterine endometrium to develop a receptive environment. This involves changes in the uterine epithelium that are tightly regulated by steroid hormones, type I interferons, cytokines, prostaglandins (PGs) and growth factors and their receptors (Forde et al. 2011, Dorniak et al. 2012, Spencer et al. 2013, Lonergan \& Forde 2014).

Many reproductive processes, such as luteolysis, PR and implantation, involve inflammation and associated up-regulation of inflammatory mediators (e.g. PGs) and recruitment of immune cells to the uterine endometrium (Jabbour et al. 2009). PGE (a vasodilator) is luteotrophic for maintaining progesterone secretion by the corpus luteum, whereas $\mathrm{PGF}_{2 \alpha}$ (a vasoconstrictor) is luteolytic (Weems et al. 2006). In PG production pathways, two series PGs, such as $\mathrm{PGE}_{2}$ and $\mathrm{PGF}_{2 \alpha^{\prime}}$ are produced from arachidonic acid (AA). PG-endoperoxide synthase isozymes (PTGS1 and PTGS2) catalyse AA into PGH2, and $\mathrm{PGH} 2$ is converted into PGEs by the action of PGE synthase (PGES), and into PGFs by the action of PGF synthase (PGFS) (Wathes et al. 2007). There are many isoforms for both PGES and PGFS. Previous studies have shown that mPTGES1 and AKR1B1 are the predominant 
isoforms for $\mathrm{PGE}_{2}$ and $\mathrm{PGF}_{2 \alpha}$ production, respectively, in bovine endometrium (Fortier et al. 2008).

During PR, IFNT inhibits the up-regulation of oxytocin (OXT) receptors (OXTR) in the uterine epithelium, thereby preventing the pulsatile release of $\mathrm{PGF}_{2 \alpha^{\prime}}$ which is necessary for luteolysis (Wathes \& Lamming 1995, Mann et al. 1999). In contrast, basal release of PGs, such as $\mathrm{PGE}_{2}$ and $\mathrm{PGF}_{2 \alpha^{\prime}}$ from both the conceptus and the maternal uterine endometrium rises during early pregnancy (Zarco et al. 1988, Dorniak et al. 2013). This increased PG production may facilitate the effects of IFNT on the expression of endometrial type I IFN-stimulated genes (ISGs), a vital component of PR (Spencer et al. 2013).

Bovine viral diarrhoea virus (BVDV), a singlestranded RNA virus, causes widespread infection in the cattle worldwide. The reproductive system, including the uterine endometrium, is a major site for infection, maintenance and spreading of the virus (Grooms 2004, Lanyon et al. 2014). BVDV infection can have a significant impact on all stages of pregnancy, including causing early embryonic death, such that reproductive losses are one of the most important consequences of the disease (Grooms 2004). Our recent studies demonstrated that infection of bovine endometrial cells in vitro with non-cytopathic BVDV (ncpBVDV) caused many significant changes in pathways associated with innate immunity, particularly those associated with type I interferon signalling (Oguejiofor et al. 2015a). ncpBVDV thus inhibited the expression of many ISGs that are also involved in PR, such as IFITS, BST2, MX2, OAS1, USP18 and RSAD2 (Forde et al. 2011). Some of these genes are also regulated by PGs (Spencer et al. 2013). In monocytes, BVDV infection stimulated the production of $\mathrm{PGE}_{2}$ (Welsh et al. 1995). When bovine endometrial cells were also exposed to bacterial lipopolysaccharide (LPS), ncpBVDV increased the expression of PLA2G4F and PTGES (mPGES1) (Oguejiofor et al. 2015a). PLA2G4F belongs to the family of PLA2 enzymes that are essential for the initial release of AA in PG biosynthesis (Tithof et al. 2007), whereas PTGES subsequently catalyses the isomerisation of $\mathrm{PGH}_{2}$ to $\mathrm{PGE}_{2}$ (Samuelsson et al. 2007).

These results suggested that ncpBVDV infection in cows may (1) interfere with the normal PR signals in response to IFNT and (2) increase endometrial $\mathrm{PGE}_{2}$ production following bacterial infection, potentially compromising the innate immune response. To explore these possibilities further, this study mimicked PR by stimulating bovine endometrial cells with IFNT in the presence or absence of ncpBVDV infection and investigated the effects of these treatments on PG signalling pathways.

\section{Materials and methods}

All reagents were purchased from Sigma or BDH Merck Ltd (Leics, UK) unless otherwise stated. All culture media used included 50,000 units/L penicillin and $50 \mathrm{mg} / \mathrm{L}$ streptomycin. All culture media and serum used were certified BVDV free.

\section{Animal, cell isolation and culture}

Fresh and apparently healthy uteri from cows in the early luteal phase of the oestrous cycle were collected at the local abattoir. Uterine endometrial cells (a mixture of primary epithelial and stromal cells) were isolated and cultured following the methods described previously (Cheng et al. 2013, Oguejiofor et al. 2015b). Briefly, under sterile conditions, strips of intercaruncular endometrium were separated and put into serum-free Dulbecco's Modified Eagle's Medium/Nutrient Mixture F-12 Ham (DMEM/F12 medium) (Sigma) and chopped into $1 \mathrm{~mm}^{3}$ cubes. They were digested for $90 \mathrm{~min}$ at $37^{\circ} \mathrm{C}$ in a medium containing $100 \mathrm{mg}$ bovine serum albumin (BSA; Sigma), $50 \mathrm{mg}$ trypsin III (Worthington, Lakewood, NJ, USA) and $50 \mathrm{mg}$ collagenase A (Roche) per $100 \mathrm{~mL}$ of Hanks' balanced salt solution (HBSS; Sigma). After filtration through a $100 \mu \mathrm{m}$ mesh into $50 \mathrm{~mL}$ falcon vials, the suspension was re-suspended with HBSS containing 10\% foetal bovine serum (FBS; PAA, Somerset, UK) and $3 \mu \mathrm{g} / \mathrm{mL}$ trypsin inhibitor (Sigma) and centrifuged at $100 \mathrm{~g}$ at $10^{\circ} \mathrm{C}$ for $10 \mathrm{~min}$. After two repetitions of the above washing procedures, the cells were suspended in the culture medium (DMEM/F12 medium with $10 \%$ FBS) and plated in 24-well IWAKI microplates (Scitech DIV; Asahi Techno Glass, Funabashi, Japan) at $2 \mathrm{~mL}$ per well containing $0.5 \times 10^{5}$ cells (day 1 ). Culture medium was changed every $48 \mathrm{~h}$ to allow the cells to grow. The composition of the cell population was confirmed using immunocytochemical staining validated in our laboratory (Oguejiofor et al. 2015b). After culturing for 8 days (day 8), epithelial cells comprised about $90 \%$ and stromal cells about $10 \%$ of the population. Contamination of immune cells was negligible $(<0.001 \%)$.

\section{BVDV test for experimental samples}

The experiment was designed to use BVDV-free bovine endometrial samples and FBS. The examination was carried out using a PCR method reported previously (Vilcek et al. 1994, Pinheiro de Oliveira et al. 2013). The primer pair for the PCR was as follows: forward (ATGCCCWTAGTAGGACTAGCA; position 108-128) and reverse (TCAACTCCATGTGCCATGTAC; position 395-375) with an expected product size of $288 \mathrm{bp}$, which are the highly conserved 5' non-coding/non-structural coding regions of the pestivirus BVDV genome strain NADL (Vilcek et al. 1994). Total RNAs in the uterine endometrial tissue and FBS were extracted using a Qiagen RNA Lipids Mini kit (Qiagen) following the supplied protocol. RNA was reverse transcribed into cDNA using a cDNA synthesis kit supplied by PCRBiosystems (London, UK), and PCR was performed using the G-Storm thermal cycler (G-Storm Ltd, Somerset, UK) and Qiagen Multiple PCR kit (Qiagen). The testing system also included a BVDV-positive control prepared using the pT7Blue-2 blunt vector, linearised (Novagen, Cambridge, MA, USA), reverse transcription-negative controls and a housekeeping gene $\beta$-actin (ACTB, see Table 1 for its primers) to verify that PCR reagents and reaction volumes were free of genomic DNA contamination. The above testing was carried out on the day of collection of uterus in parallel with the cell isolation and culture. The endometrium initially tested negative for BVDV was used for further experiments. 


\section{Propagation of ncpBVDV}

The ncpBVDV (Pe515nc strain) was acquired from the BVDV Research Group, Royal Veterinary College, UK. This strain was isolated from a cow diagnosed with mucosal disease and virologically cloned as non-cytopathogenic virus. To provide adequate infectious BVDV for the present experiments, the virus stock was propagated to achieve a $50 \%$ tissue culture infective dose $\left(\mathrm{TCID}_{50}\right)$ of $5 \times 10^{5}$ per $\mathrm{mL}$ following the method used in our group (Oguejiofor et al. 2015a).

\section{Experimental protocols}

The experiments of ncpBVDV infection and IFNT challenge were carried out in the endometrial cells from ten cows confirmed BVDV negative tested using the above method. Cells from each cow were collected as a batch and grown in two 24-well plates as described previously (day 1 ). On day 4 of the cell culture when the cells grew to approximately $70 \%$ of confluence, FBS in the culture medium was reduced to $5 \%$ (maintenance medium, MM) to prevent overgrowth of the cells. The cells from each cow were divided into four treatment groups: control (CONT), IFNT, ncpBVDV and IFNT+ncpBVDV. Wells treated with the virus were maintained in separate plates from those treated without the virus to prevent crosscontamination. For the cells designated as BVDV infected, $0.25 \mathrm{~mL}$ MM containing Pe515nc BVDV at a multiplicity of infection (MOI) of 0.1 was added for $3 \mathrm{~h}$ to allow for virus infection. The same procedures, but with $0.25 \mathrm{~mL} \mathrm{MM}$ only, were carried out for the cells designated as non-infected controls. The volume in all wells was made up to $1 \mathrm{~mL}$ with MM and the medium was changed after 2 days. IFNT treatment was carried 4 days after infection (day 8). For the wells specified for IFNT treatment, the medium was replaced with $1 \mathrm{~mL}$ MM containing $100 \mathrm{ng}$ IFNT (recombinant ovine IFNT; Cell Sciences, Canton, MA, USA) and incubated for $24 \mathrm{~h}$. The other wells were changed and incubated with $1 \mathrm{~mL} \mathrm{MM}$. The spent medium was harvested (on day 9) and stored at $-20^{\circ} \mathrm{C}$ for PG quantification, and the treated cells were used for total RNA extraction.

\section{Assessment of BVDV cell infection and cell viability}

Bovine endometrial cell infection with ncpBVDV was confirmed using both the PCR method with the extracted RNA as described above and an indirect enzyme (alkaline phosphatase) immunostaining procedure as described previously (Oguejiofor et al. 2015a). The cell viability after exposure to the infection and treatment was assessed using an MTS reduction assay method as described previously (Oguejiofor et al. 2015b).

\section{Quantification of PGs using radioimmunoassay (RIA)}

The concentrations of $\mathrm{PGE}_{2}$ and $\mathrm{PGF}_{2 \alpha}$ in the spent medium were measured with charcoal-dextran-coated RIA methods described previously (Cheng et al. 2001). The PG antisera were a kind gift from Dr N L Poyser (University of Edinburgh, Edinburgh, UK). The cross-reactivities for $\mathrm{PGE}_{2}$ antiserum were
23, 100 and $15 \%$ with $\mathrm{PGE}_{1}, \mathrm{PGE}_{2}$ and $\mathrm{PGE}_{3}$, respectively, and those for $\mathrm{PGF}_{2 \alpha}$ antiserum were 34, 100 and $25 \%$ with $\mathrm{PGF}_{1 \alpha^{\prime}}$ $\mathrm{PGF}_{2 \alpha}$ and $\mathrm{PGF}_{3 \alpha}$ respectively. The standards for $\mathrm{PGE}_{2}$ and $\mathrm{PGF}_{2 \alpha}$ were purchased from Sigma, and the tritiated tracers of $\mathrm{PGE}_{2} \quad\left(\left[5,6,8,11,12,14,15(\mathrm{n})-{ }^{3} \mathrm{H}\right]-\mathrm{PGE}_{2}\right)$ and $\mathrm{PGF}_{2 \alpha}$ $\left(\left[5,6,8,9,11,12,14,15(n)-{ }^{3} \mathrm{H}\right]-\mathrm{PGF}_{2 \alpha}\right) \quad$ were supplied by PerkinElmer. The samples were diluted $(\times 10-200)$ in the RIA buffer. This allowed the sample PG concentrations to fall within the analytical ranges of the RIAs $(0.02-5.0 \mathrm{ng} / \mathrm{mL}$ for $\mathrm{PGE}_{2}$ and $0.01-2.5 \mathrm{ng} / \mathrm{mL}$ for $\mathrm{PGF}_{2 \alpha}$ ), and the interruption from the medium contents with the RIAs was minimised, making extraction unnecessary. The limits of detection were $2 \mathrm{pg} / \mathrm{tube}$ and $1 \mathrm{pg} /$ tube for $\mathrm{PGE}_{2}$ and $\mathrm{PGF}_{2 \alpha}$ respectively. The intra-assay and inter-assay coefficients of variation were 3.5 and $6.3 \%$ for $\mathrm{PGE}_{2}(n=6)$ and 4.1 and $9.6 \%$ for $\mathrm{PGF}_{2 \alpha}$ respectively $(n=6)$.

\section{RNA extraction}

After collection of spent medium, the cells from each treatment group (six wells) were pooled and the total RNA extraction was carried out using RNeasy Mini Kits (Qiagen) following the supplier's protocol. The concentrations and purity of RNA were measured using a NanoDrop ND-1000 spectrophotometer (NanoDrop Technologies Inc., Wilminton, DE, USA).

\section{Primer design and PCR}

DNA sequences for all primers were obtained from GenBank at NCBI (http://www.ncbi.nlm.nih.gov/Database/ index.html) and the primers were designed using a "Primer 3" web-based programme (http://frodo.wi.mit.edu/primer3). Their alignment specificity and quality were checked using the Blast tool at http://www.ncbi.nlm.nih.gov/tools/primerblast/ and Amplify tool (http://www.idtdna.com/analyzer/ Applications/OligoAnalyzer/Default.aspx). The detailed information of the primers is given in Table 1 . The primers were made by Eurofins MWG Operon (Ebersberg, Germany). RNA $(1 \mu \mathrm{g})$ was reverse transcribed into cDNA using a cDNA synthesis kit supplied by PCRBiosystems following the supplier's protocol. The resulting cDNA $(20 \mu \mathrm{L})$ was diluted in nuclease-free water up to $100 \mu \mathrm{L}$.

PCR for the tested genes was performed using the G-Storm thermal cycler and Qiagen Multiple PCR kit (Qiagen), and the DNA products for each gene were used for (1) verifying the primer specificity using electrophoresis on a $2 \%(\mathrm{w} / \mathrm{v})$ agarose gel and (2) preparation of the DNA standards for each gene in the following quantitative PCR (qPCR) procedures.

\section{qPCR analysis for gene expression}

The concentrations of all the ten target genes (PTGS1, PTGS2, mPGES1, AKR1B1, PTGER2, PTGER3, PTGFR, OXTR, PGR and ESR1) and four reference genes (GAPDH, RPL19, ACTB and 18 SrRNA) were quantified using qPCR via an absolute quantification approach following the method described previously (Cheng et al. 2013). The DNA amplified from CDNA used for standards in the qPCR assay was purified using a QIAquick PCR purification kit (Qiagen), and their quality and concentrations were determined with the NanoDrop 
ND-1000 spectrophotometer. Eight standards were prepared from 1 to $1 \times 10^{-7} \mathrm{ng} / \mathrm{mL}$. Annealing and amplicon-specific melting temperatures of the primers were determined using a gradient function of the qPCR machine (CFX96 Real-Time System DNA; Bio-Rad Laboratories) with eight identical reactions containing $2 \mathrm{ng}$ of DNA standard, $10 \mu \mathrm{L}$ Sygreen Mix (PCRBiosystems), $0.8 \mu \mathrm{L}$ of each $10 \mu \mathrm{M}$ forward and reverse primer, and nucleate-free water added up to $20 \mu \mathrm{L}$. The optimised annealing temperatures are given in Table 1.

To quantify the expression levels of each gene, the qPCR assay contained a standard curve, no template control (NTC) and a sample cDNA in duplicate with the same final volume on CFX96 Real-Time Systems (Bio-Rad). Each well contained $5 \mu \mathrm{L}$ cDNA standard or samples, $10 \mu \mathrm{L}$ Sygreen Mix (PCRBiosystems), $0.8 \mu \mathrm{L}$ of $10 \mu \mathrm{M}$ forward primer, $0.8 \mu \mathrm{L}$ reverse primer and $3.4 \mu \mathrm{L}$ nucleate-free water following the protocol supplied by PCRBiosystems and using the optimised annealing temperatures shown in Table 1. This included an initial Taq activation for 2 min followed by 38 cycles of denaturation $\left(95^{\circ} \mathrm{C}\right)$, annealing (the annealing temperatures are given in Table 1 ) and extension $\left(63^{\circ} \mathrm{C}\right)$. An ampliconspecific fluorescence acquisition reading based on the melting temperature obtained in the above gradient test was applied to avoid any noise from smaller non-specific products such as dimers before the product acquisition. The results were analysed using the CFX Manager Software package (Bio-Rad). The limit of quantification was $1 \times 10^{-6}$ to $1 \times 10^{-7} \mathrm{ng} / \mathrm{mL}$ for all tested genes. In order to minimise variation, RT for all samples was performed in one assay. For each gene, the standards and all samples were prepared under the same conditions in a single plate with the same master mix of reagents.

\section{Statistical data analyses}

All values are summarised as mean \pm S.E.M. The values of gene expression generated by qPCR were normalised as femto gram per micro gram reverse-transcribed total RNA. The PG ratios were calculated as $\mathrm{PGE}_{2}: \mathrm{PGF}_{2 \alpha}$. Statistical data analysis was carried out using analysis of variance (ANOVA) with repeated measurements for the PG data and ANOVA with randomised block design for the gene expression data via a linear mixed effect model built in SPSS V22, in which the differences between treatments (CONT, ncpBVDV, IFNT and their combination) were taken as fixed effect and cows as random effect or subject for repeated measurement. Statistical significance was considered at $P<0.05$. Logarithmic transformation was applied if the data were not normally distributed. Where statistical significance was achieved in ANOVA, Fisher's LSD multiple comparisons based on the least square means were performed to identify the differences between the treatment pairs.

\section{Results}

Initial testing using PCR on the day of collection confirmed that all the uteri selected were free of BVDV. Successful infection of the ncpBVDV-infected cells only after treatment was confirmed using both PCR and immunocytochemistry as described previously (Oguejiofor et al. 2015b) (data not shown). Neither the individual nor the combined treatments affected cell viability at the doses used as confirmed using an MTS reduction assay method.

Table 1 Oligonucleotide primer sequence information.

\begin{tabular}{|c|c|c|c|c|}
\hline Gene & Primer sequence $\left(5^{\prime}-3^{\prime}\right)$ & GenBank accession no. & Product length (bp) & Annealing temperature $\left({ }^{\circ} \mathrm{C}\right)$ \\
\hline PTGS1 & Forward: CACAGTGCGTTCCAACCTTATC & NM_001105323.1 & 163 & 63.3 \\
\hline PTGS2 & $\begin{array}{l}\text { Forward: TACTGGAAGCCTAGCACTTTC G } \\
\text { Reverse: TGAATGAGGTAAAGGGACAGCC }\end{array}$ & NM_174445.2 & 112 & 61.4 \\
\hline mPGES1 & $\begin{array}{l}\text { Forward: TGTGTTTCCCCGTGTGTC } \\
\text { Reverse: ACTGAGTCTCTGTTTGCTTTTC }\end{array}$ & NM_174443.2 & 167 & 59.5 \\
\hline$A K R 1 B 1$ & $\begin{array}{l}\text { Forward: TACCTGGACCTCTACCTCATCC } \\
\text { Reverse: CGTCCAGGTATCCACGAAATCT }\end{array}$ & NM_001012519.1 & 120 & 64.5 \\
\hline PTGER2 & $\begin{array}{l}\text { Forward: CTACTTCTACCAGCGCCGAG } \\
\text { Reverse: TACGTGGTCTGCTTGTGTCC }\end{array}$ & NM_174588.2 & 165 & 64.5 \\
\hline PTGER3 & $\begin{array}{l}\text { Forward: GTGGTCATCGTCCTCTACCTGT } \\
\text { Reverse: CTTCATGTGGCTTGAGTACCAG }\end{array}$ & NM_181032.1 & 186 & 61.4 \\
\hline PTGFR & $\begin{array}{l}\text { Forward: TGGTGTTCTCTGGTCTGTGC } \\
\text { Reverse: AAAGCACACCCCACTCAACA }\end{array}$ & XM_010803367.1 & 140 & 60 \\
\hline OXTR & $\begin{array}{l}\text { Forward: TCATCATCGCCATGCTCCTG } \\
\text { Reverse: CGGAATGAGCAGCAGAGGAA }\end{array}$ & NM_174134.2 & 118 & 63.3 \\
\hline$P G R$ & $\begin{array}{l}\text { Forward: AGGAGTTGTCCCTAGCTCACAG } \\
\text { Reverse: GCAGCAATAACCTCAGACATCA }\end{array}$ & NM_001205356.1 & 162 & 59 \\
\hline ESR1 & $\begin{array}{l}\text { Forward: TCAGGCTACCATTACGGAGTTT } \\
\text { Reverse: CCACTTCATAGCACTTGCGTAG }\end{array}$ & NM_001001443.1 & 169 & 59 \\
\hline GAPDH & $\begin{array}{l}\text { Forward: GGTCACCAGGGCTGCTTTTA } \\
\text { Reverse: TTCCCGTTCTCTGCCTTGAC }\end{array}$ & NM_001034034.2 & 147 & 61.4 \\
\hline RPL19 & $\begin{array}{l}\text { Forward: TCGATGCCGGAAAAACAC } \\
\text { Reverse: ATTCTCATCCTCCTCATCCAG }\end{array}$ & NM 001040516 & 119 & 59 \\
\hline$A C T B$ & $\begin{array}{l}\text { Forward: GAAATCGTCCGTGACATCAA } \\
\text { Reverse: AGGAAGGAAGGCTGGAAGAG }\end{array}$ & NM_173979.3 & 182 & 61.4 \\
\hline $18 S r R N A$ & $\begin{array}{l}\text { Forward: CGGCGACGACCCATTCGAAC } \\
\text { Reverse: GAATCGAACCCTGATTCCCCGTC }\end{array}$ & AY779625 & 99 & 64.5 \\
\hline
\end{tabular}


Effect of ncpBVDV, IFNT and their combination on PG production by uterine endometrial cells

The results showing the effect of ncpBVDV, IFNT and their combination on PG production by uterine endometrial cells are given in Fig. 1. ANOVA with repeated measurements showed that the differences of $\mathrm{PGE}_{2}$ concentrations between treatment groups were significant $(P<0.018)$. Fisher's LSD multiple comparisons illustrated that both IFNT challenge and ncpBVDV infection alone significantly stimulated $\mathrm{PGE}_{2}$ production $(P<0.05)$, whereas the stimulatory effect was neutralised when IFNT was combined with ncpBVDV $(P<0.05)$ (Fig. 1A).

Compared with CONT, IFNT challenge appeared to decrease $\mathrm{PGF}_{2 \alpha}$ production; however, statistical significance was not achieved $(P>0.05)$. In the cells infected with ncpBVDV, concentrations of $\mathrm{PGF}_{2 \alpha}$ were significantly lower than in the CONT cells $(P<0.05)$. When the ncpBVDV-infected cells were challenged with IFNT, $\mathrm{PGF}_{2 \alpha}$ concentrations were significantly lower than in the CONT cells $(P<0.05)$, and the concentrations were slightly lower than in the cells infected with ncpBVDV alone, although the difference was not statistically significant $(P>0.05)$ (Fig. 1B).

Compared with the CONT cells, in the ncpBVDVinfected cells, the ratios of $\mathrm{PGE}_{2}$ to $\mathrm{PGF}_{2 \alpha}$ significantly increased $(P<0.05)$. Both IFNT and IFNT+ncpBVDV treatments appeared to increase the ratio of $\mathrm{PGE}_{2}: \mathrm{PGF}_{2 \alpha}$ produced; however, the differences were not statistically significant due to large variations between animals $(P>0.05)$ (Fig. 1C).

Effect of ncpBVDV, IFNT and their combination on the expression of selected reference genes in uterine endometrial cells

We selected 18SrRNA, ACTB, RPL19 and GAPDH as potential reference genes for qPCR. The results showed, however, that the expression of 18SrRNA, ACTB and RPL19 was significantly altered by IFNT, ncpBVDV or their combination $(P<0.05-0.01)$. Only GAPDH expression was not affected by any of the above treatments $(P>0.05)$ (Fig. 2A, B, C and D). Subsequent gene expression measurements have therefore been presented as absolute values given as femto gram per micro gram reverse-transcribed total RNA.

Effect of ncpBVDV, IFNT and their combination on expression of PGR, ESR1 and OXTR in uterine endometrial cells

In the bovine endometrial cells, expression of OXTR mRNA was relatively higher $(1879 \pm 419 \mathrm{fg} / \mu \mathrm{g}$ RNA), whereas ESR1 mRNA expression was very low $(0.003 \pm 0.0008 \mathrm{fg} / \mu \mathrm{g}$ RNA). The effects of all tested treatments on the expression of PGR, ESR 1 and OXTR mRNA were moderate and no statistical significance
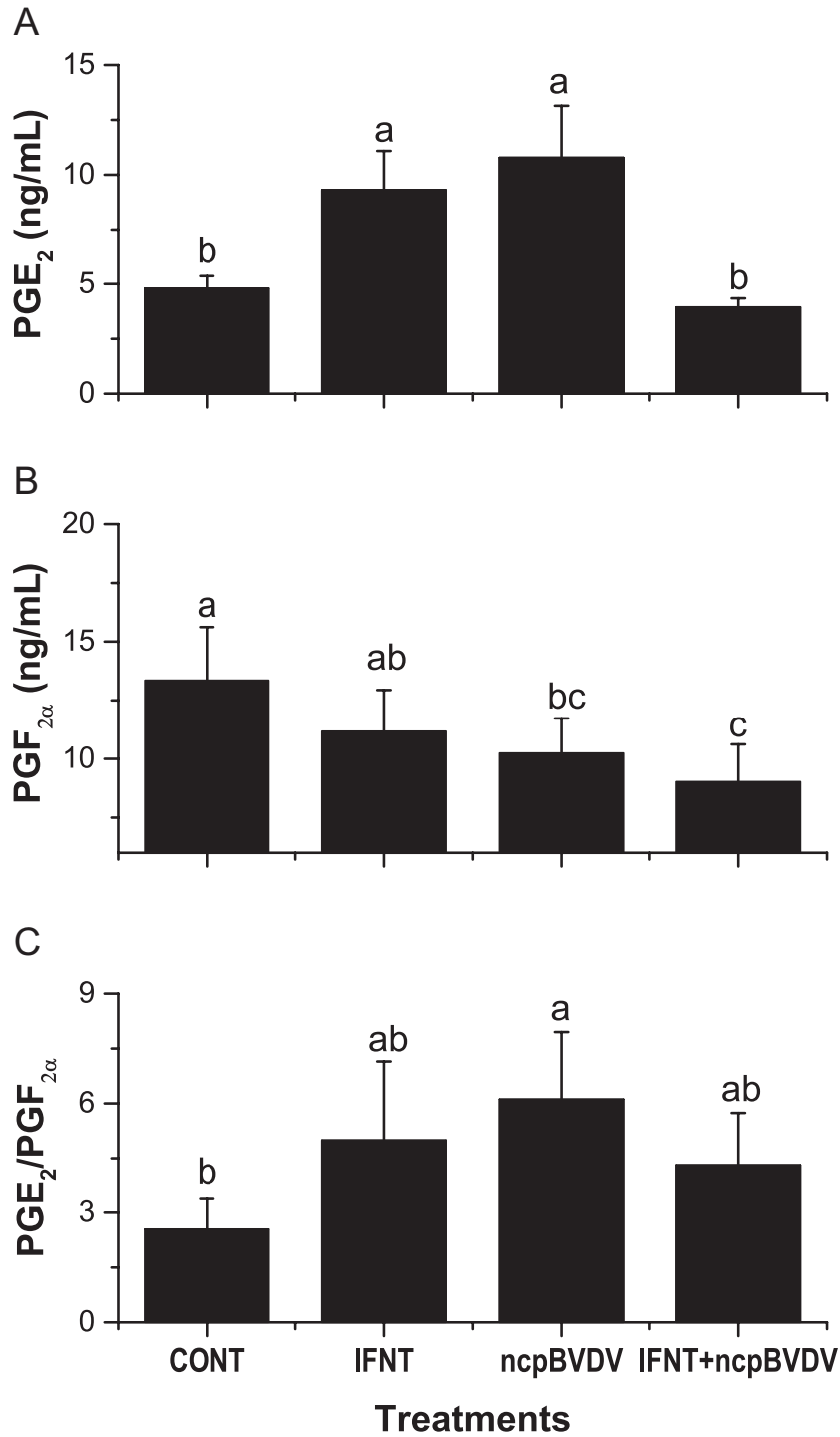

Figure 1 Effect of non-cytopathic bovine viral diarrhoea virus (ncpBVDV), interferon- $\tau$ (IFNT) and their combination on prostaglandin ( $\mathrm{PG}$ ) $\mathrm{E}_{2}$ production $(\mathrm{A}), \mathrm{PGF}_{2 \alpha}$ production $(\mathrm{B})$ and $\mathrm{PGE}_{2}: \mathrm{PGF}_{2 \alpha}$ ratio $(\mathrm{C})$ by uterine endometrial cells isolated from BVDV-free cyclic cows. When cells were grown to approximately $70 \%$ confluence after 4 days of culture, ncpBVDV was inoculated at 0 or a multiplicity of infection of 0.1 . Four days following inoculation, the cells were challenged with IFNT at 0 or $100 \mathrm{ng} / \mathrm{mL}$ for $24 \mathrm{~h}$. The spent medium was harvested for PG analysis. There were three replicates per treatment for each cow and ten cows per treatment. CONT: control without ncpBVDV and IFNT. The columns labelled with different letters were significantly different at $P<0.05-0.01(\mathrm{a}>\mathrm{b}>\mathrm{c})$.

was achieved as tested using ANOVA with randomised block design (Fig. 3A, B and C).

Effect of ncpBVDV, IFNT and their combination on the expression of PTGS1, PTGS2, MPGES1 and AKR1B1 in uterine endometrial cells

In the cells infected with ncpBVDV, expression of PTGS1 mRNA was significantly higher than in the CONT 
cells $(P<0.05)$. IFNT challenge significantly induced PTGS1 mRNA expression $(P<0.01)$; however, in the presence of ncpBVDV infection, this stimulatory effect was completely neutralised $(P<0.05)$ (Fig. 4A). In the cells infected with ncpBVDV, PTGS2 mRNA expression appeared to be lower than other groups; however, statistical significance was not achieved $(P>0.05)$ (Fig. 4B). Figure 4C demonstrated that ncpBVDV infection stimulated $m P G E S 1$ mRNA expression by up to three-fold $(P=0.0003)$ compared with the CONT cells, whereas neither IFNT nor IFNT+ncpBVDV challenge affected its expression $(P>0.05)$. As shown in Fig. 4D, neither IFNT nor ncpBVDV alone altered $A K R 1 B 1$ mRNA expression significantly $(P>0.05)$, whereas
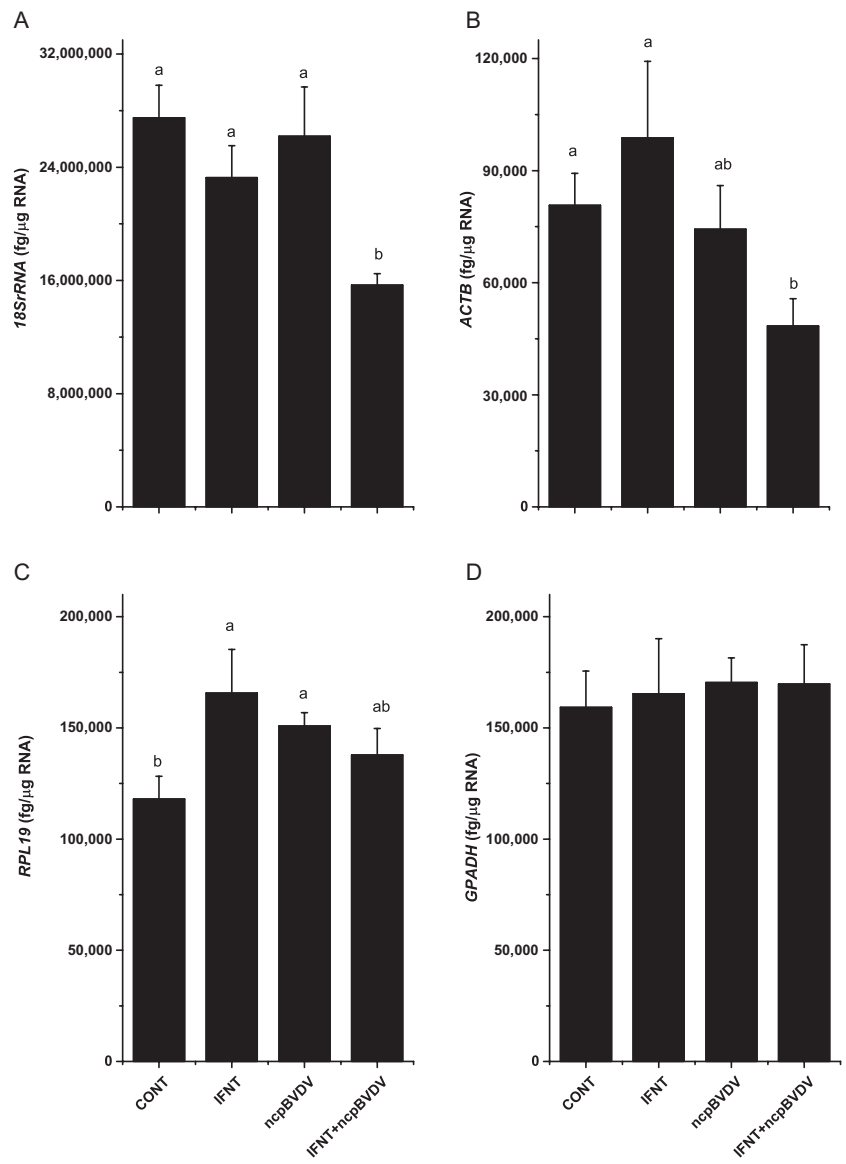

Figure 2 Effect of non-cytopathic bovine viral diarrhoea virus (ncpBVDV), interferon- $\tau$ (IFNT) and their combination on the reference gene expression of (A) 18SrRNA, (B) ACTB, (C) RPL19 and (D) GAPDH by uterine endometrial cells isolated from BVDV-free cyclic cows. When cells were grown to approximately $70 \%$ confluence after 4 days of culture, ncpBVDV was inoculated at 0 or a multiplicity of infection of 0.1 . Four days following inoculation, the cells were challenged with IFNT at 0 or $100 \mathrm{ng} / \mathrm{mL}$ for $24 \mathrm{~h}$. Total RNA was extracted from the treated cells and the gene expression was quantified using an absolute qPCR approach. There were three replicates per treatment for each cow and ten cows per treatment. CONT: control without ncpBVDV and IFNT. The columns labelled with different letters were significantly different at $P<0.05-0.01(\mathrm{a}>\mathrm{b})$. their combination led to a significant decrease in its expression $(P<0.05)$.

\section{Effect of ncpBVDV, IFNT and their combination on the expression of PTGER2, PTGER3 and PTGFR in uterine endometrial cells}

As shown in Fig. $5 \mathrm{~A}$ and $\mathrm{C}$, the expression of PTGER2 and PTGFR mRNA was not significantly changed by treatment with IFNT, ncpBVDV or their combination $(P>0.05)$. Compared with the CONT, treatment with ncpBVDV alone only moderately reduced PTGER3
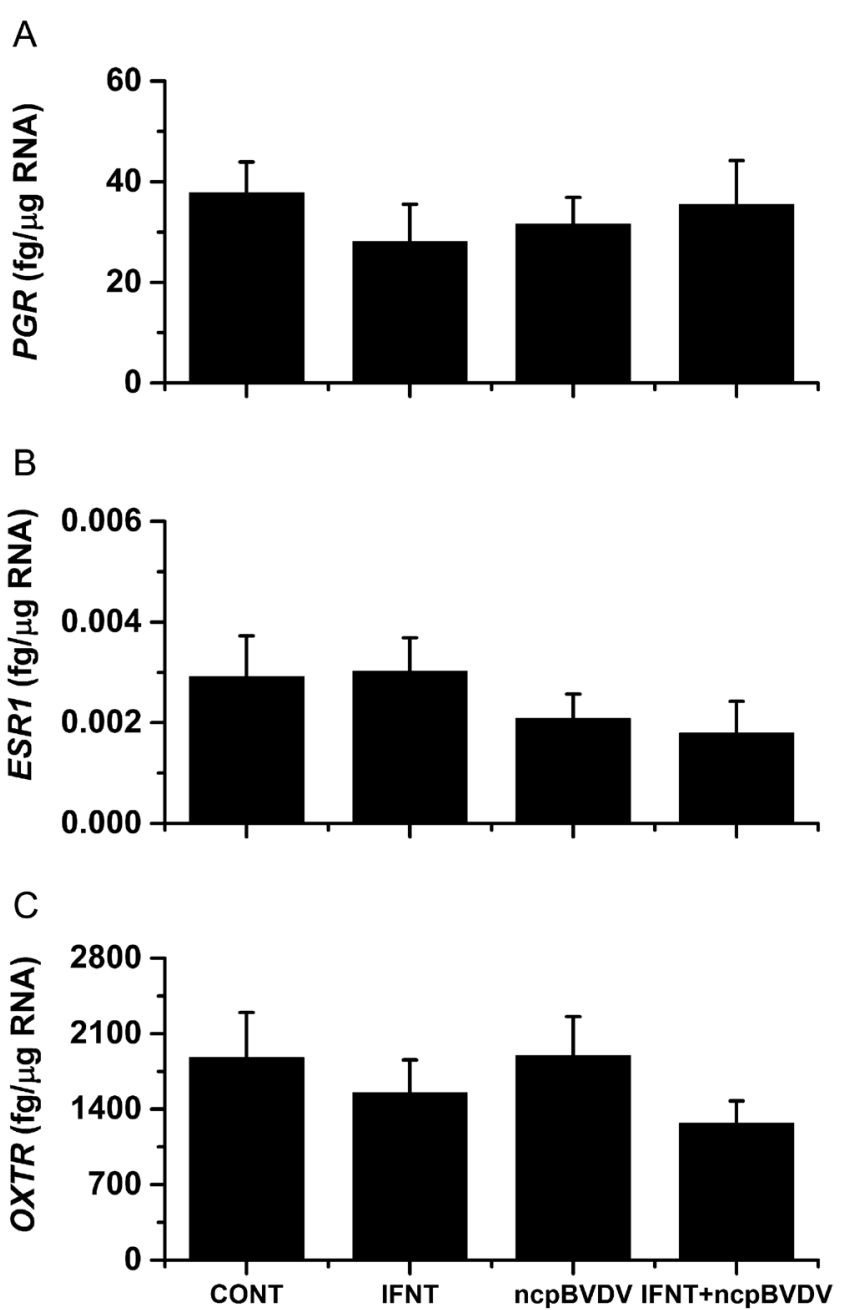

Treatments

Figure 3 Effect of non-cytopathic bovine viral diarrhoea virus (ncpBVDV), interferon- $\tau$ (IFNT) and their combination on (A) $P G R$, (B) ESR1 and (C) OXTR expression by uterine endometrial cells isolated from BVDV-free cyclic cows. When cells were grown to approximately $70 \%$ confluence after 4 days of culture, ncpBVDV was inoculated at 0 or a multiplicity of infection of 0.1 . Four days following inoculation, the cells were challenged with IFNT at 0 or $100 \mathrm{ng} / \mathrm{mL}$ for $24 \mathrm{~h}$. Total RNA was extracted from the treated cells and the gene expression was quantified using an absolute qPCR approach. There were three replicates per treatment for each cow and ten cows per treatment. CONT: control without ncpBVDV and IFNT. 
mRNA expression $(P>0.05)$. In the cells stimulated with IFNT, PTGER3 mRNA expression was up-regulated by up to 2.5 -fold $(P<0.01)$, whereas in the presence of ncpBVDV infection, the stimulatory effect of IFNT on PTGER3 mRNA expression was intensively inhibited $(P<0.01)$ and the expression was even lower than that in the CONT cells $(P<0.01)$ (Fig. 5B).

\section{Discussion}

$\mathrm{PR}$ in cows is initiated by IFNT release from the conceptus acting on the uterine endometrium leading
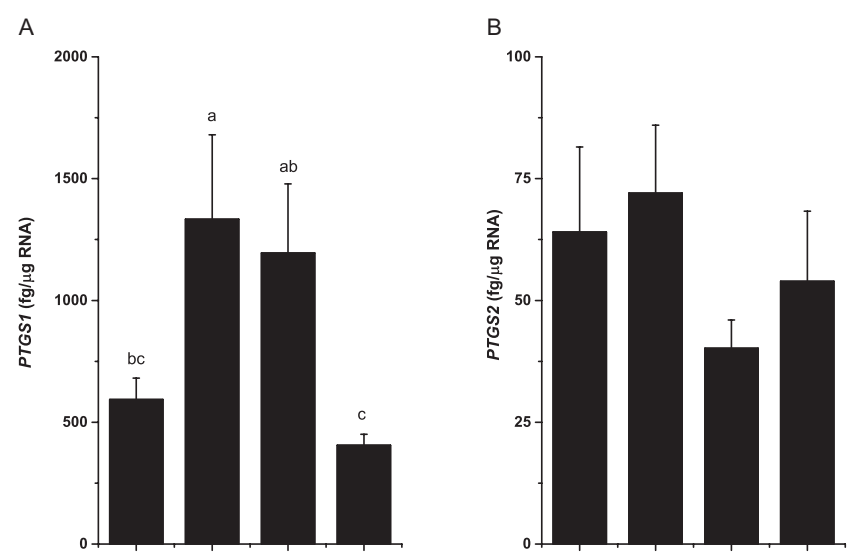

C

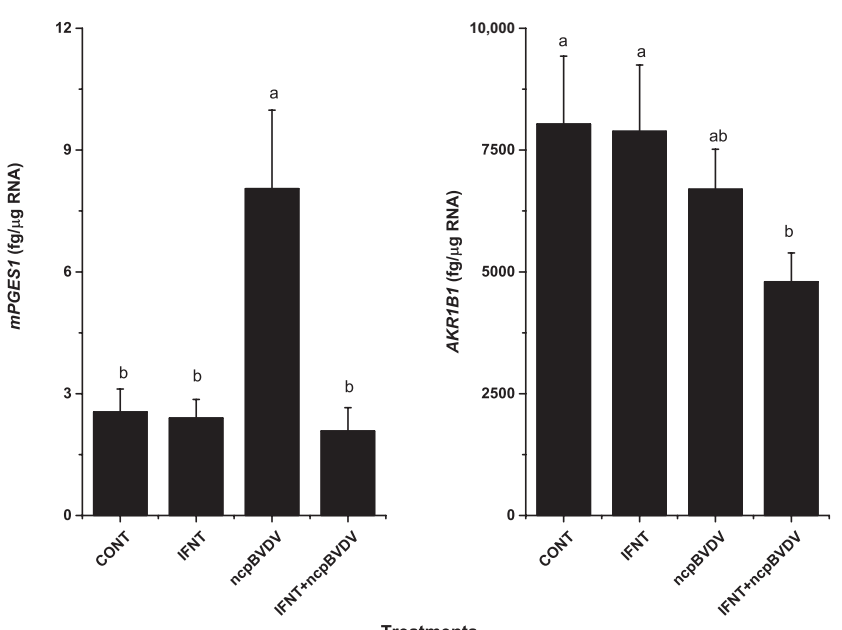

Figure 4 Effect of non-cytopathic bovine viral diarrhoea virus (ncpBVDV), interferon- $\tau$ (IFNT) and their combination on mRNA expression of (A) PTGS1, (B) PTCS2, (C) mPGES1 and (D) AKR1B1 by uterine endometrial cells isolated from BVDV-free cyclic cows. When cells were grown to approximately $70 \%$ confluence after 4 days of culture, ncpBVDV was inoculated at 0 or a multiplicity of infection of 0.1. Four days following inoculation, the cells were challenged with IFNT at 0 or $100 \mathrm{ng} / \mathrm{mL}$ for $24 \mathrm{~h}$. Total RNA was extracted from the treated cells and the gene expression was quantified using an absolute qPCR approach. There were three replicates per treatment for each cow and ten cows per treatment. CONT: control without ncpBVDV and IFNT. The columns labelled with different letters were significantly different at $P<0.05-0.01(\mathrm{a}>\mathrm{b}>\mathrm{c})$. to maintenance of the corpus luteum. Regulation of the synthesis and release of $\mathrm{PGE}_{2}$ and $\mathrm{PGF}_{2 \alpha}$ are crucial to this process (Bazer 2013, Lonergan \& Forde 2014). Failure of PR is a significant risk factor for embryonic mortality (Diskin et al. 2011, Forde et al. 2011). BVDV infection can cause early embryonic death (Grooms 2004); however, little evidence is currently available on the mechanisms involved. In this study, we investigated the effect of BVDV infection on PG production and signalling pathways in bovine endometrium. We have demonstrated that (1) ncpBVDV infection induced an endocrine switch of $\mathrm{PG}$ production and signalling from $\mathrm{PGF}_{2 \alpha}$ to $\mathrm{PGE}_{2}$ and (2) IFNT stimulates uterine $\mathrm{PGE}_{2}$ production and its signalling pathway; however, this stimulatory effect is abolished by ncpBVDV infection.

In addition to PR, IFNT possesses antiviral, antiproliferative and immunosuppressive activities (Pontzer et al. 1988, 1991, Kohara et al. 2012). It was previously reported that the replication of ncpBVDV was completely suppressed by bovine IFNT treatment in cultured bovine muscular cells (Kohara et al. 2012). In our study, after IFNT challenge for 24h, ncpBVDV RNA was well detected in all infected endometrial cells using a PCR method, whereas it was negative in the ncpBVDV-free cells. Using a qPCR method, we confirmed that there was no significant difference in the ncpBVDV mRNA expression between the ncpBVDV and IFNT+ncpBVDV groups. Kohara et al. (2012) carried out infection of their cells after IFNT treatment, whereas in our study, infection was carried out before challenge. The different cell types used with their different structures and cellular signalling systems may also be important in this response. Our data support previous findings that the uterine endometrium is one of the major sites for infection, maintenance and spreading of BVDV in the cattle population (Grooms 2004, Lanyon et al. 2014).

In the non-pregnant uterine endometrium, $\mathrm{PGF}_{2 \alpha}$ is predominantly produced by uterine epithelial cells and $\mathrm{PGE}_{2}$ by stromal cells (Danet-Desnoyers et al. 1994, Charpigny et al. 1999). In this study, the endometrial cells produced significant amounts of both $\mathrm{PGE}_{2}$ $(4.8 \pm 0.5 \mathrm{ng} / \mathrm{mL})$ and $\mathrm{PGF}_{2 \alpha}(13.3 \pm 2.2 \mathrm{ng} / \mathrm{mL})$. Together with the immunocytochemical staining results, this confirmed the presence of both epithelial and stromal cell populations. The paracrine interactions between these two cell types are important for the investigation of overall response of the endometrium to IFNT challenge and ncpBVDV infection.

In ruminants, although IFNT inhibits the pulsatile release of $\mathrm{PGF}_{2 \alpha}$ by the uterine epithelium, the basal release of $\mathrm{PGE}_{2}$ and $\mathrm{PGF}_{2 \alpha}$ from both the conceptus and the endometrium increases during early pregnancy (Zarco et al. 1988, Dorniak et al. 2013). PGs secreted by both epithelial and stromal cells co-ordinate with the IFNT to regulate uterine endometrial functions. This is important to develop a receptive environment for conceptus development, thereby promoting elongation 

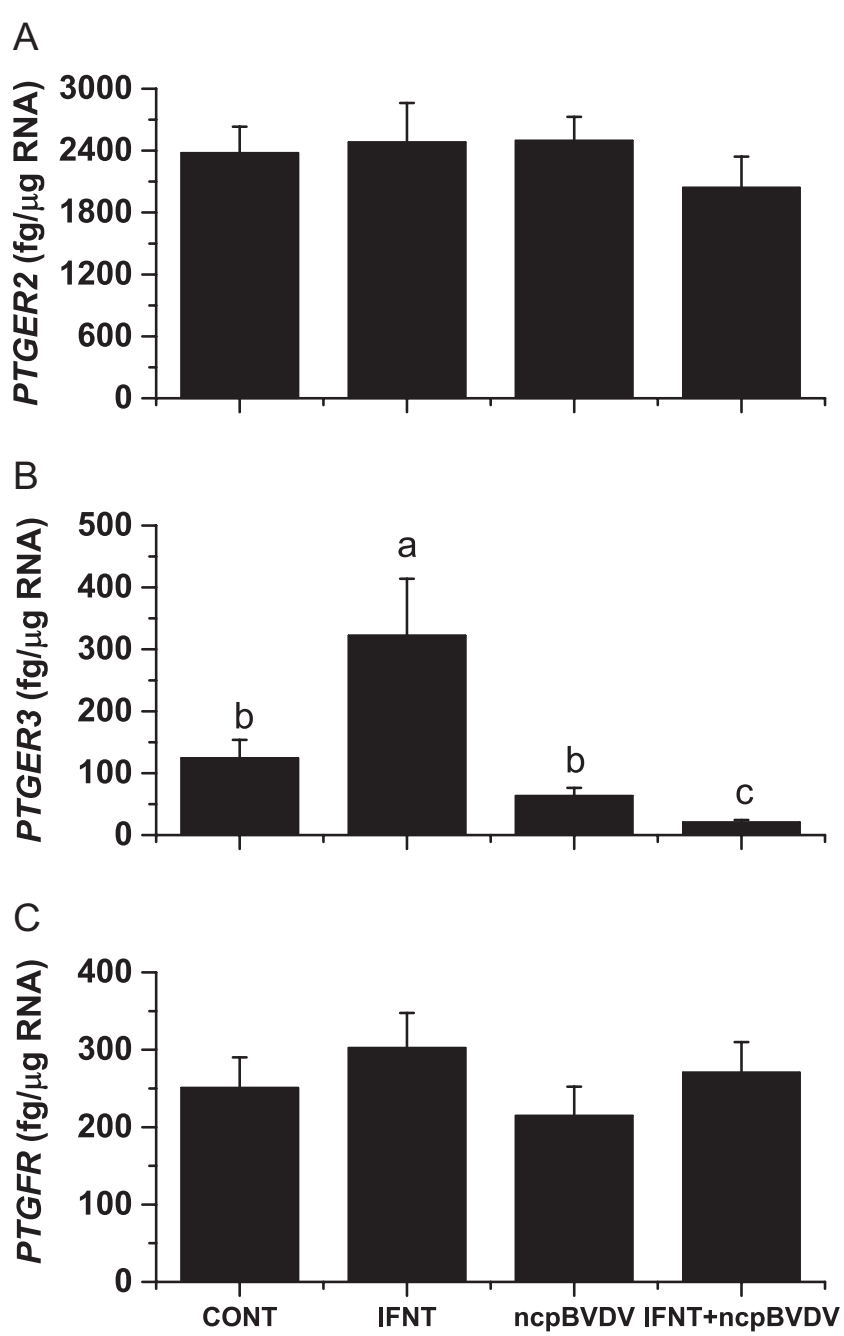

Treatments

Figure 5 Effect of non-cytopathic bovine viral diarrhoea virus (ncpBVDV), interferon- $\tau$ (IFNT) and their combination on mRNA expression of (A) PTGER2, (B) PTGER3 and (C) PTGFR by uterine endometrial cells isolated from BVDV-free cyclic cows. When cells were grown to approximately $70 \%$ confluence after 4 days of culture, ncpBVDV was inoculated at 0 or a multiplicity of infection of 0.1 . Four days following inoculation, the cells were challenged with IFNT at 0 or $100 \mathrm{ng} / \mathrm{mL}$ for $24 \mathrm{~h}$. Total RNA was extracted from the treated cells and the gene expression was quantified using an absolute qPCR approach. There were three replicates per treatment for each cow and ten cows per treatment. CONT: control without ncpBVDV and IFNT. The columns labelled with different letters significantly different at $P<0.05-0.01(a>b>c)$

and implantation (Bazer 2013, Dorniak et al. 2013). In support of this, intra-uterine infusion of meloxicam, a PTGS inhibitor, prevented uterine PG production and led to failure of conceptus elongation in ewes (Diskin et al. 2011). In cows, successful development to term and delivery of a live calf could be predicted by the expression of PTCS2 in day 7 blastocysts (Bazer 2013). In this study, when the endometrial cells isolated from cyclic cows were given IFNT for $24 \mathrm{~h}$, their $\mathrm{PGE}_{2}$ production was significantly up-regulated, whereas the $\mathrm{PGF}_{2 \alpha}$ production was not altered. This agreed with the previous finding that IFNT does not affect the expression of PTGS2, the rate-limiting enzyme in PG synthesis, but does stimulate $\mathrm{PGE}_{2}$ production by cells of the bovine uterus (Dorniak et al. 2013). We also found that IFNT challenge increased PTGS1 and PTGER3 gene expression by up to 2.5 -fold. Such an increase in both $\mathrm{PGE}_{2}$ and its receptor indicates that IFNT favours the $\mathrm{PGE}_{2}$ signalling pathway that would benefit maintenance of the corpus luteum as $\mathrm{PGE}_{2}$ is a luteotrophin (Pratt et al. 1977, Dorniak et al. 2013). In the presence of ncpBVDV infection, however, the stimulatory effects of IFNT on $\mathrm{PGE}_{2}$ production and its receptor PTGER3 expression were neutralised, and the $\mathrm{PGE}_{2}$ concentrations were even slightly lower than in the CONT cells. When the ncpBVDV-infected cells were treated with IFNT, basal $\mathrm{PGF}_{2 \alpha}$ production and $A K R 1 B 1 \mathrm{mRNA}$ expression were also lower than the CONT. AKR1B1 is a predominant isoform for $\mathrm{PGF}_{2 \alpha}$ production (Fortier et al. 2008). Therefore, decreased or disrupted basal PG production may contribute to failure of pregnancy establishment and maintenance following ncpBVDV infection.

These results also suggest that IFNT treatment may act on uterine epithelial and stromal compartments differentially as $\mathrm{PGE}_{2}$ is produced by stromal cells and PGF $_{2 \alpha}$ by epithelial cells. This supports previous studies in ewes that have shown cell-specific effects of IFNT for many ISGs crucial for developing a receptive environment for conceptus implantation. During early pregnancy or following intrauterine IFN treatment, the expression of the majority of progesterone-independent ISGs such as RSAD2 (radical S-adenosyl methionine domain containing 2) and IFIH1 (interferon-induced with helicase $C$ domain 1 ) was increased in endometrial stroma, glands and immune cells but not in the luminal epithelium. In contrast, some non-classical ISGs such as LGALS15 (galectin 15), CTSL (cathespin L) and CST3 (cystatin C), which require progesterone priming, were predominantly expressed in the endometrial luminal epithelium and superficial glandular epithelium (Song et al. 2007, Bazer et al. 2008, Spencer et al. 2013).

It is interesting to note that ncpBVDV infection alone increased uterine $\mathrm{PGE}_{2}$ production and decreased $\mathrm{PGF}_{2 \alpha}$ production, whereas expression of PTGS2, AKR1B1 and PTCFR all tended to be lower than in the CONT cells. Lower PTCS2 and AKR1B1 expression may in part contribute to the decreased $\mathrm{PGF}_{2 \alpha}$ production, whereas lower PTGFR expression would further impair the $\mathrm{PGF}_{2 \alpha}$ signalling pathway. In contrast, the expression of mPGES1, a principle isoform for $\mathrm{PGE}_{2}$ production (Fortier et al. 2008), was up-regulated by about fourfold, leading to an increased uterine $\mathrm{PGE}_{2}$ generation and an increased ratio of $\mathrm{PGE}_{2}$ to $\mathrm{PGF}_{2 \alpha}$. These results show that ncpBVDV infection induced an endocrine switch from $\mathrm{PGF}_{2 \alpha}$ to $\mathrm{PGE}_{2}$ production. As $\mathrm{PGF}_{2 \alpha}$ is an immune enhancer and $\mathrm{PGE}_{2}$ is an immune suppressor 
(Lewis 2003, Herath et al. 2009), this switch provides a mechanism whereby BVDV infection can predispose affected animals to uterine infection. Similarly, bacterial LPS treatment increased PGE $_{2}$ production and decreased $\mathrm{PGF}_{2 \alpha}$ production in bovine endometrium (Herath et al. 2009). Our previous studies demonstrated that numerous innate immune responses mounted following an LPS challenge was also significantly suppressed in ncpBVDV-infected bovine uterine endometrial cells (Oguejiofor et al. 2015a). Together, these results support the suggestion that cows infected with BVDV may be predisposed to develop endometritis due to bacterial infection following calving. This may in turn also contribute to early embryonic death and failure of pregnancy establishment (Gilbert 2011).

In ruminants, OXTR are up-regulated in the uterine epithelium following a period of exposure to high progesterone levels (Wathes \& Lamming 1995, Wathes et al. 1996). Once these are present, OXT binding to its receptor drives pulsatile release of $\mathrm{PGF}_{2 \alpha^{\prime}}$ so starting the process of luteolysis (Poyser 1995, McCracken et al. 1999). The initial increase in OXTR is independent of oestradiol regulation (Robinson et al. 1999, Leung \& Wathes 2000, Mann et al. 2013). However, there is a subsequent increase in ESR1 through which oestradiol stimulates the expression of further OXTR in the superficial glandular epithelium and stroma (Wathes \& Hamon 1993, Robinson et al. 1999). IFNT secreted from the conceptus acts on the uterine epithelium to inhibit the expression of both OXTR and ESR 1, thereby inhibiting the release of luteolytic pulses of $\mathrm{PGF}_{2 \alpha}$ and leading to establishment of pregnancy (Mann et al. 1999, Bazer 2013). In this study, both OXTR and ESR $1 \mathrm{mRNA}$ expression was numerically lower following IFN treatment; however, the differences did not achieve statistical significance because OXTR mRNA was already highly up-regulated before the IFN treatment was commenced.

During early pregnancy, IFNT also acts on maternal endometrium to establish a nutrient transport system to support further growth and development of the conceptus (Bazer 2013). In this study, we tested four reference genes to validate the qPCR assay. These were highly conserved housekeeping genes encoding proteins involved in key cellular processes. It was interesting to note that expression of $18 S r R N A$ and ACTB mRNA was significantly inhibited by ncpBVDV infection in the presence of IFNT challenge, whereas expression of the ribosomal protein RPL19 mRNA was increased by both the individual treatments. Only GAPDH remained constant across all the four treatments. This suggests another mechanism by which ncpBVDV infection may affect the survival of the conceptus to disrupt PR. Based on these results, we used an absolute quantification qPCR approach. Great care should be taken while measuring gene expression in reproductive systems using relative quantification qPCR as its accuracy depends on the stable expression of the selected reference genes.
In summary, IFNT challenge stimulated uterine PTGS1 and PTGER3 mRNA expression and $\mathrm{PGE}_{2}$ production; however, these stimulatory effects were neutralised in the presence of ncpBVDV infection. The interruption of IFNT-induced PG production and signalling by BVDV infection may directly cause failure of PR. ncpBVDV infection stimulated PTGS1 and mPGES1 mRNA expression and moderately suppressed $A K R 1 B 1$ expression, leading to increased $\mathrm{PGE}_{2}$ and decreased $\mathrm{PGF}_{2 \alpha}$ concentrations and an increase in $\mathrm{PGE}_{2}: \mathrm{PGF}_{2 \alpha}$ ratios in bovine uterine endometrium. This endocrine switch of $\mathrm{PG}$ production from $\mathrm{PGF}_{2 \alpha}$ to $\mathrm{PGE}_{2}$ may decrease uterine immunity to predispose the animals to uterine diseases, indirectly leading to failure of PR. Our results thus suggest a mechanism whereby ncpBVDV infection in cows may cause early embryonic death and reduced fertility.

\section{Declaration of interest}

The authors declare that there is no conflict of interest that could be perceived as prejudicing the impartiality of the research reported.

\section{Funding}

This research did not receive any specific grant from any funding agency in the public, commercial or not-for-profit sector.

\section{Acknowledgements}

The authors would like to thank $\operatorname{Dr} \mathrm{N} L$ Poyser for his generous gift of $\mathrm{PGE}_{2}$ and $\mathrm{PGF}_{2 \alpha}$ antibodies.

\section{References}

Bazer FW 2013 Pregnancy recognition signaling mechanisms in ruminants and pigs. Journal of Animal Science and Biotechnology 423. (doi:10.1186/2049-1891-4-23)

Bazer FW, Burghardt RC, Johnson GA, Spencer TE \& Wu G 2008 Interferons and progesterone for establishment and maintenance of pregnancy: interactions among novel cell signaling pathways. Reproductive Biology 8 179-211.

Charpigny G, Reinaud P, Creminon C \& Tamby JP 1999 Correlation of increased concentration of ovine endometrial cyclooxygenase 2 with the increase in PGE2 and PGD2 in the late luteal phase. Journal of Reproduction and Fertility 117 315-324. (doi:10.1530/jrf.0.1170315)

Cheng Z, Robinson RS, Pushpakumara PG, Mansbridge RJ \& Wathes DC 2001 Effect of dietary polyunsaturated fatty acids on uterine prostaglandin synthesis in the cow. Journal of Endocrinology 171 463-473. (doi:10.1677/joe.0.1710463)

Cheng Z, Abayasekara DR, Ward F, Preece DM, Raheem KA \& Wathes DC 2013 Altering n-3 to n-6 polyunsaturated fatty acid ratios affects prostaglandin production by ovine uterine endometrium. Animal Reproduction Science 143 38-47.

Danet-Desnoyers G, Wetzels C \& Thatcher WW 1994 Natural and recombinant bovine interferon tau regulate basal and oxytocin-induced secretion of prostaglandins F2 alpha and E2 by epithelial cells and stromal cells in the endometrium. Reproduction, Fertility, and Development 6 193-202. (doi:10.1071/RD9940193) 
De Vries A 2006 Economic value of pregnancy in dairy cattle. Journal of Dairy Science 89 3876-3885. (doi:10.3168/jds.S0022-0302(06)72430-4)

Diskin MG, Parr MH \& Morris DG 2011 Embryo death in cattle: an update. Reproduction, Fertility, and Development 24 244-251. (doi:10.1071/ RD11914)

Dorniak P, Bazer FW, Wu G \& Spencer TE 2012 Conceptus-derived prostaglandins regulate endometrial function in sheep. Biology of Reproduction 87 1-7. (doi:10.1095/biolreprod.112.101691)

Dorniak P, Bazer FW \& Spencer TE 2013 Physiology and endocrinology symposium: biological role of interferon tau in endometrial function and conceptus elongation. Journal of Animal Science 91 1627-1638.

Forde N, Carter F, Spencer TE, Bazer FW, Sandra O, Mansouri-Attia N, Okumu LA, McGettigan PA, Mehta JP, McBride R et al. 2011 Conceptusinduced changes in the endometrial transcriptome: how soon does the cow know she is pregnant? Biology of Reproduction 85 144-156. (doi:10.1095/biolreprod.110.090019)

Fortier MA, Krishnaswamy K, Danyod G, Boucher-Kovalik S \& Chapdalaine $\mathbf{P} 2008$ A postgenomic integrated view of prostaglandins in reproduction: implications for other body systems. Journal of Physiology and Pharmacology: an Official Journal of the Polish Physiological Society 59 (Supplement 1) 65-89.

Gilbert RO 2011 The effects of endometritis on the establishment of pregnancy in cattle. Reproduction, Fertility, and Development 24 252-257. (doi:10.1071/RD11915)

Grooms DL 2004 Reproductive consequences of infection with bovine viral diarrhea virus. Veterinary Clinics of North America. Food animal Practice 20 5-19. (doi:10.1016/j.cvfa.2003.11.006)

Herath S, Lilly ST, Fischer DP, Williams EJ, Dobson H, Bryant CE \& Sheldon IM 2009 Bacterial lipopolysaccharide induces an endocrine switch from prostaglandin F2alpha to prostaglandin E2 in bovine endometrium. Endocrinology 150 1912-1920. (doi:10.1210/en.20081379)

Jabbour HN, Sales KJ, Catalano RD \& Norman JE 2009 Inflammatory pathways in female reproductive health and disease. Reproduction 138 903-919. (doi:10.1530/REP-09-0247)

Kimura K, Spate LD, Green MP, Murphy CN, Seidel GE Jr \& Roberts RM 2004 Sexual dimorphism in interferon-tau production by in vivoderived bovine embryos. Molecular Reproduction and Development 67 193-199.

Kohara J, Nishikura Y, Konnai S, Tajima M \& Onuma M 2012 Effects of interferon-tau on cattle persistently infected with bovine viral diarrhea virus. The Japanese Journal of Veterinary Research $6063-70$.

Lanyon SR, Hill FI, Reichel MP \& Brownlie J 2014 Bovine viral diarrhoea: pathogenesis and diagnosis. Veterinary Journal 199 201-209. (doi:10.1016/j.tvjl.2013.07.024)

Leung ST \& Wathes DC 2000 Oestradiol regulation of oxytocin receptor expression in cyclic bovine endometrium. Journal of Reproduction and Fertility 119 287-292.

Lewis G 2003 Role of ovarian progesterone and potential role of prostaglandin F2alpha and prostaglandin E2 in modulating the uterine response to infectious bacteria in postpartum ewes. Journal of Animal Science 81 285-293.

Lonergan P \& Forde N 2014 Maternal-embryo interaction leading up to the initiation of implantation of pregnancy in cattle. Animal 8 (Supplement 1) 64-69. (doi:10.1017/S1751731114000470)

Mann GE, Lamming GE, Robinson RS \& Wathes DC 1999 The regulation of interferon-tau production and uterine hormone receptors during early pregnancy. Journal of Reproduction and Fertility. Supplement $\mathbf{5 4}$ 317-328.

Mann GE, Wathes DC \& Robinson RS 2013 The progesterone receptor antagonist, onapristone has differential effects on the timing and control of the luteolytic mechanism depending on timing of administration in sheep. Molecular and Cellular Endocrinology 376 1-11. (doi:10.1016/j. mce.2013.06.001)

McCracken JA, Custer EE \& Lamsa JC 1999 Luteolysis: a neuroendocrinemediated event. Physiological Reviews $79263-323$.

Oguejiofor CF, Cheng Z, Abudureyimu A, Anstaett OL, Brownlie J, Fouladi-Nashta AA \& Wathes DC 2015a Global transcriptomic profiling of bovine endometrial immune response in vitro. II. Effect of bovine viral diarrhea virus on the endometrial response to lipopolysaccharide. Biology of Reproduction 93101.

Oguejiofor CF, Cheng Z, Abudureyimu A, Fouladi-Nashta AA \& Wathes DC $2015 b$ Global transcriptomic profiling of bovine endometrial immune response in vitro. I. Effect of lipopolysaccharide on innate immunity. Biology of Reproduction 93100.

Pinheiro de Oliveira TF, Fonseca AA Jr, Camargos MF, de Oliveira AM, Pinto Cottorello AC, Souza Ados R, de Almeida IG \& Heinemann MB 2013 Detection of contaminants in cell cultures, sera and trypsin. Biologicals 41 407-414. (doi:10.1016/j.biologicals.2013.08.005)

Pontzer CH, Torres BA, Vallet JL, Bazer FW \& Johnson HM 1988 Antiviral activity of the pregnancy recognition hormone ovine trophoblast protein-1. Biochemical and Biophysical Research Communications 152 801-807. (doi:10.1016/S0006-291X(88)80109-8)

Pontzer CH, Bazer FW \& Johnson HM 1991 Antiproliferative activity of a pregnancy recognition hormone, ovine trophoblast protein-1. Cancer Research 51 5304-5307.

Poyser NL 1995 The control of prostaglandin production by the endometrium in relation to luteolysis and menstruation. Prostaglandins, Leukotrienes, and Essential Fatty Acids 53 147-195. (doi:10.1016/09523278(95)90115-9)

Pratt BR, Butcher RL \& Inskeep EK 1977 Antiluteolytic effect of the conceptus and of PGE2 in ewes. Journal of Animal Science 45 784-791.

Robinson RS, Mann GE, Lamming GE \& Wathes DC 1999 The effect of pregnancy on the expression of uterine oxytocin, oestrogen and progesterone receptors during early pregnancy in the cow. Journal of Endocrinology 160 21-33.

Samuelsson B, Morgenstern R \& Jakobsson PJ 2007 Membrane prostaglandin E synthase-1: a novel therapeutic target. Pharmacological Reviews 59 207-224. (doi:10.1124/pr.59.3.1)

Song G, Bazer FW \& Spencer TE 2007 Pregnancy and interferon tau regulate RSAD2 and IFIH1 expression in the ovine uterus. Reproduction 133 285-295. (doi:10.1530/REP-06-0092)

Spencer TE, Forde N, Dorniak P, Hansen TR, Romero JJ \& Lonergan P 2013 Conceptus-derived prostaglandins regulate gene expression in the endometrium prior to pregnancy recognition in ruminants. Reproduction 146 377-387. (doi:10.1530/REP-13-0165)

Tithof PK, Roberts MP, Guan W, Elgayyar M \& Godkin JD 2007 Distinct phospholipase A2 enzymes regulate prostaglandin E2 and F2alpha production by bovine endometrial epithelial cells. Reproductive Biology and Endocrinology 516.

Vilcek S, Herring AJ, Herring JA, Nettleton PF, Lowings JP \& Paton DJ 1994 Pestiviruses isolated from pigs, cattle and sheep can be allocated into at least three genogroups using polymerase chain reaction and restriction endonuclease analysis. Archives of Virology 136 309-323.

Wathes DC \& Hamon M 1993 Localization of oestradiol, progesterone and oxytocin receptors in the uterus during the oestrous cycle and early pregnancy of the ewe. Journal of Endocrinology 138 479-492. (doi:10.1677/joe.0.1380479)

Wathes DC \& Lamming GE 1995 The oxytocin receptor, luteolysis and the maintenance of pregnancy. Journal of Reproduction and Fertility. Supplement 49 53-67.

Wathes DC, Mann GE, Payne JH, Riley PR, Stevenson KR \& Lamming GE 1996 Regulation of oxytocin, oestradiol and progesterone receptor concentrations in different uterine regions by oestradiol, progesterone and oxytocin in ovariectomized ewes. Journal of Endocrinology 151 375-393.

Wathes DC, Abayasekara DR \& Aitken RJ 2007 Polyunsaturated fatty acids in male and female reproduction. Biology of Reproduction 77 190-201.

Weems CW,Weems YS \& Randel RD 2006 Prostaglandins and reproduction in female farm animals. Veterinary Journal 171 206-228. (doi:10.1016/j. tvjl.2004.11.014)

Welsh MD, Adair BM \& Foster JC 1995 Effect of BVD virus infection on alveolar macrophage functions. Veterinary Immunology and Immunopathology 46 195-210. (doi:10.1016/0165-2427(94)05366-Z)

Zarco L, Stabenfeldt GH, Basu S, Bradford GE \& Kindahl H 1988 Modification of prostaglandin F-2 alpha synthesis and release in the ewe during the initial establishment of pregnancy. Journal of Reproduction and Fertility 83 527-536. (doi:10.1530/jrf.0.0830527)

Received 11 December 2015

First decision 29 January 2016

Revised manuscript received 9 February 2016

Accepted 7 March 2016 